\title{
Health Care, Family, and Community Factors Associated with Mental, Behavioral, and Developmental Disorders and Poverty Among Children Aged 2-8 Years - United States, 2016
}

Robyn A. Cree, PhD ${ }^{1,2}$; Rebecca H. Bitsko²; PhD; Lara R. Robinson, $\mathrm{PhD}^{2}$; Joseph R. Holbrook, PhD²; Melissa L. Danielson, MSPH²; Camille Smith, EdS ${ }^{3}$; Jennifer W. Kaminski, $\mathrm{PhD}^{2}$; Mary Kay Kenney, $\mathrm{PhD}^{4}$; Georgina Peacock, $\mathrm{MD}^{2}$

Childhood mental, behavioral, and developmental disorders (MBDDs) are associated with adverse outcomes that can persist into adulthood $(1,2)$. Pediatric clinical settings are important for identifying and treating MBDDs (3). Early identification and treatment of MBDDs can promote healthy development for all children (4), especially those living in poverty who are at increased risk for MBDDs $(3,5)$ but might have reduced access to care (6). CDC analyzed data from the 2016 National Survey of Children's Health (NSCH) on MBDDs, risk factors, and use of federal assistance programs (e.g., Supplemental Nutrition Assistance Program [SNAP]) to identify points to reach children in poverty. In line with previous research $(3,6)$, compared with children in higher-income households, those in lower-income households more often had ever received a diagnosis of an MBDD (22.1\% versus $13.9 \%$ ), and less often had seen a health care provider in the previous year $(80.4 \%$ versus 93.8\%). Among children living below $200 \%$ of the federal poverty level (FPL) who did not see a health care provider in the previous year, seven of 10 were in families receiving at least one public assistance benefit. Public assistance programs might offer collaboration opportunities to provide families living in poverty with information, co-located screening programs or services, or connection to care.

$\mathrm{NSCH}$ is a national, cross-sectional, web-based and paperbased survey funded and directed by the Health Resources and Services Administration's Maternal and Child Health Bureau that is representative of noninstitutionalized children aged 0-17 years in the United States.* The U.S. Census Bureau conducted the 2016 NSCH using address-based sampling and created weights to account for oversampling and potential

\footnotetext{
*https://mchb.hrsa.gov/data/national-surveys/data-user.
}

nonresponse biases. ${ }^{\dagger}$ Parents were asked, "Has a doctor or other health care provider ever told you that this child has (specified MBDDs)?" A child was considered to have ever had an MBDD if their parent reported one or more of the following: anxiety problems, depression, attention-deficit/hyperactivity disorder, behavioral or conduct problems, Tourette syndrome, autism spectrum disorder, learning disability, intellectual disability, developmental delay, or language problems. Parents also responded to questions related to factors associated with

\footnotetext{
${ }^{\dagger}$ https://census.gov/content/dam/Census/programs-surveys/nsch/techdocumentation/nonresponse-bias-analysis/NSCH\%202016\%20 Nonresponse\%20Bias\%20Analysis.pdf.
}

\section{INSIDE}

1384 Drug, Opioid-Involved, and Heroin-Involved Overdose Deaths Among American Indians and Alaska Natives — Washington, 1999-2015

1388 Rabies in a Dog Imported from Egypt Connecticut, 2017

1392 Trends and Gaps in National Blood Transfusion Services - 14 Sub-Saharan African Countries, 2014-2016

1397 Notes from the Field: Infections After Receipt of Bacterially Contaminated Umbilical Cord BloodDerived Stem Cell Products for Other Than Hematopoietic or Immunologic Reconstitution United States, 2018

1400 QuickStats

Continuing Education examination available at https://www.cdc.gov/mmwr/cme/conted_info.html\#weekly.

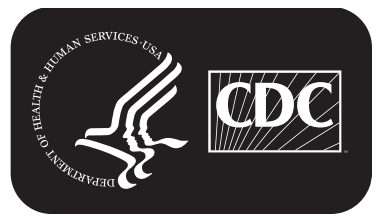


$\operatorname{MBDDs}(1,3)$, including household income, health insurance, components of a medical home, difficulty getting by on the family's income, parent emotional support, neighborhood condition (e.g., litter or vandalism), neighborhood amenities (e.g., sidewalks or parks), and parental mental or physical health, as well as whether they received public assistance (e.g., SNAP; Women, Infants, and Children [WIC]; free or reduced price meals at school; or cash assistance). ${ }^{\$}$

Parents of 50,212 children participated in the survey, resulting in an interview completion rate of $69.7 \%$ and a weighted response rate of $40.7 \%$. Analyses were restricted to children aged 2-8 years with nonmissing data on MBDD diagnosis and age $(16,912$ children). Data missing on race $(0.3 \%)$, ethnicity $(0.5 \%)$, sex $(0.1 \%)$, and FPL $(16.6 \%)$ were imputed using hot-deck imputation (a method for handling missing data in which missing values are replaced with observed responses from "similar" units) and regression methods. Differences in demographic, health care, family, and community factors by MBDD status were assessed using weighted prevalence estimates, prevalence ratios (PRs), 95\% confidence intervals (CIs), and Wald chi-square tests. Prevalence of MBDDs, health care, family, and community factors were compared by FPL category. Weighted prevalence estimates, PRs, and 95\% CIs

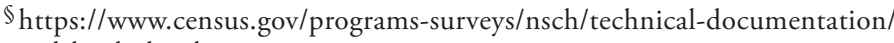
codebooks.html.

https://census.gov/content/dam/Census/programs-surveys/nsch/techdocumentation/methodology/2016-NSCH-Methodology-Report.pdf.
}

were calculated. To further explore whether federal assistance programs are possible points to reach children living in poverty, 4,410 children living below $200 \%$ of the FPL who had and had not seen a health care provider in the past year, both with and without MBDDs, were compared by whether their families received public assistance. Statistical software was used to account for the complex survey design.

Overall, $17.4 \%$ of children aged $2-8$ years had at least one MBDD (Table 1). Child sex, age, and race/ethnicity varied by MBDD status. Compared with children without MBDDs, those with MBDDs more often lived in the lowest income category $(<100 \%$ of FPL; PR $=1.4)$ and less often in the highest category ( $\geq 400 \%$ of FPL; PR $=0.8)$. Prevalences of most risk factors (e.g., child care problems, and lack of support in neighborhood) were higher among children with MBDDs than among those without MBDDs.

Prevalence of MBDDs was higher in each consecutive decreasing income level compared with the highest level ( $\geq 400 \%$ of FPL) (Table 2 ); estimates of MBDDs ranged from $13.9 \%$ among those in the highest income level $(\geq 400 \%$ of FPL) to $22.1 \%$ among those in the lowest level $(<100 \%$ of FPL). A lower percentage of children in lower-income households saw a health care provider in the past 12 months (80.4\%) and a higher percentage did not receive needed care $(5 \%)$, compared with children in the highest income level $(93.8 \%$ and $0.8 \%$, respectively). Similar patterns across income levels were found for most health care, family, and community factors (e.g., increasing prevalences of the risk factors as household

The MMWR series of publications is published by the Center for Surveillance, Epidemiology, and Laboratory Services, Centers for Disease Control and Prevention (CDC), U.S. Department of Health and Human Services, Atlanta, GA 30329-4027.

Suggested citation: [Author names; first three, then et al., if more than six.] [Report title]. MMWR Morb Mortal Wkly Rep 2018;67:[inclusive page numbers]

\section{Centers for Disease Control and Prevention Robert R. Redfield, MD, Director \\ Anne Schuchat, MD, Principal Deputy Director Leslie Dauphin, PhD, Acting Associate Director for Science \\ Barbara Ellis, PhD, MS, Acting Director, Office of Science Quality Chesley L. Richards, MD, MPH, Deputy Director for Public Health Scientific Services}

William R. Mac Kenzie, MD, Acting Director, Center for Surveillance, Epidemiology, and Laboratory Services

\section{MMWR Editorial and Production Staff (Weekly)}

Charlotte K. Kent, PhD, MPH, Acting Editor in Chief, Executive Editor Jacqueline Gindler, MD, Editor

Mary Dott, MD, MPH, Online Editor

Teresa F. Rutledge, Managing Editor

Douglas W. Weatherwax, Lead Technical Writer-Editor Glenn Damon, Soumya Dunworth, PhD, Teresa M. Hood, MS, Technical Writer-Editors

Matthew L. Boulton, MD, MPH Virginia A. Caine, MD

Katherine Lyon Daniel, PhD

Jonathan E. Fielding, MD, MPH, MBA

David W. Fleming, MD

William E. Halperin, MD, DrPH, MPH
MMWR Editorial Board Timothy F. Jones, MD, Chairman Robin Ikeda, MD, MPH Phyllis Meadows, PhD, MSN, RN Jewel Mullen, MD, MPH, MPA Jeff Niederdeppe, $\mathrm{PhD}$ Patricia Quinlisk, MD, MPH
Martha F. Boyd, Lead Visual Information Specialist Maureen A. Leahy, Julia C. Martinroe, Stephen R. Spriggs, Tong Yang, Visual Information Specialists Quang M. Doan, MBA, Phyllis H. King, Terraye M. Starr, Moua Yang, Information Technology Specialists
Stephen C. Redd, MD, Patrick L. Remington, MD, MPH Carlos Roig, MS, MA William Schaffner, MD Morgan Bobb Swanson, BS 
TABLE 1. Prevalence of demographic, health care, family, and community factors, by ever having any mental, behavioral, or developmental disorder (MBDD)* among children aged 2-8 years - National Survey of Children's Health, United States, 2016

\begin{tabular}{|c|c|c|c|c|}
\hline & Any MBDD & No MBDD & & \\
\hline Characteristic & $\%(95 \% \mathrm{Cl})^{\dagger}$ & $\%(95 \% \mathrm{Cl})^{\dagger}$ & prevalence ratio $(95 \% \mathrm{Cl})$ & p-value ${ }^{\S}$ \\
\hline Overall & $17.4(16.2-18.7)$ & $82.6(81.3-83.8)$ & - & - \\
\hline $\begin{array}{l}\text { Child sex } \\
\text { Male? }\end{array}$ & $66.7(63.0-70.1)$ & $47.8(46.0-49.6)$ & $1.4(1.3-1.5)$ & $<0.001^{\S}$ \\
\hline $\begin{array}{l}\text { Child age group (yrs) } \\
2-3 \\
4-5 \\
6-8\end{array}$ & $\begin{array}{l}18.0(15.1-21.3) \\
25.0(21.7-28.5) \\
57.0(53.1-60.8)\end{array}$ & $\begin{array}{l}30.4(28.9-32.0) \\
29.2(27.6-30.9) \\
40.4(38.5-42.2)\end{array}$ & $\begin{array}{l}0.6(0.5-0.7) \\
0.9(0.7-1.0) \\
1.4(1.3-1.5)\end{array}$ & $\begin{array}{r}<0.001^{\S} \\
0.028^{\S} \\
<0.001^{\S}\end{array}$ \\
\hline $\begin{array}{l}\text { Child race/ethnicity** } \\
\text { White, non-Hispanic } \\
\text { Black, non-Hispanic } \\
\text { Hispanic } \\
\text { Other, non-Hispanic }\end{array}$ & $\begin{array}{r}53.6(49.6-57.5) \\
13.8(11.2-16.9) \\
24.2(20.1-28.7) \\
8.4(7.1-10.0)\end{array}$ & $\begin{array}{l}51.7(49.9-53.6) \\
11.5(10.3-12.8) \\
24.4(22.4-26.5) \\
12.4(11.5-13.5)\end{array}$ & $\begin{array}{l}1.0(1.0-1.1) \\
1.2(1.0-1.5) \\
1.0(0.8-1.2) \\
0.7(0.6-0.8)\end{array}$ & $\begin{array}{r}0.405 \\
0.137 \\
0.940 \\
<0.001^{\S}\end{array}$ \\
\hline $\begin{array}{l}\text { Parent education } \\
\text { Less than high school } \\
\text { High school } \\
\text { More than high school }\end{array}$ & $\begin{array}{r}8.7(6.0-12.4) \\
19.9(16.7-23.6) \\
71.4(67.1-75.3)\end{array}$ & $\begin{array}{r}7.7(6.2-9.5) \\
17.2(15.6-18.8) \\
75.2(73.1-77.1)\end{array}$ & $\begin{array}{l}1.1(0.7-1.7) \\
1.2(1.0-1.4) \\
0.9(0.9-1.0)\end{array}$ & $\begin{array}{l}0.577 \\
0.154 \\
0.107\end{array}$ \\
\hline $\begin{array}{l}\text { Language } \\
\text { Primary language other than English }\end{array}$ & $11.0(7.8-15.4)$ & $15.5(13.7-17.4)$ & $0.7(0.5-1.0)$ & $0.035^{\S}$ \\
\hline $\begin{array}{l}\text { Urban/Rural designations }{ }^{\dagger \dagger} \\
\text { Urban } \\
\text { Large rural } \\
\text { Small rural } \\
\text { Isolated }\end{array}$ & $\begin{array}{r}89.6(87.6-91.3) \\
6.2(4.8-8.0) \\
2.6(1.9-3.5) \\
1.6(1.1-2.4)\end{array}$ & $\begin{array}{r}91.1(90.4-91.8) \\
5.1(4.6-5.7) \\
2.2(1.9-2.5) \\
1.6(1.3-2.0)\end{array}$ & $\begin{array}{l}1.0(1.0-1.0) \\
1.2(0.9-1.6) \\
1.2(0.9-1.7) \\
1.0(0.6-1.5)\end{array}$ & $\begin{array}{l}0.136 \\
0.198 \\
0.302 \\
0.960\end{array}$ \\
\hline $\begin{array}{l}\text { Federal poverty level }{ }^{\S \S} \\
\geq 400 \% \\
200 \%-399 \% \\
100 \%-199 \% \\
<100 \%\end{array}$ & $\begin{array}{l}22.9(19.8-26.3) \\
27.0(22.8-31.7) \\
24.2(20.4-28.4) \\
25.9(22.1-30.0)\end{array}$ & $\begin{array}{l}29.8(28.2-31.5) \\
28.7(27.0-30.4) \\
22.3(20.5-24.2) \\
19.2(17.4-21.1)\end{array}$ & $\begin{array}{l}0.8(0.7-0.9) \\
0.9(0.8-1.1) \\
1.1(0.9-1.3) \\
1.4(1.1-1.6)\end{array}$ & $\begin{array}{l}0.001^{\S} \\
0.488 \\
0.409 \\
0.002^{\S}\end{array}$ \\
\hline 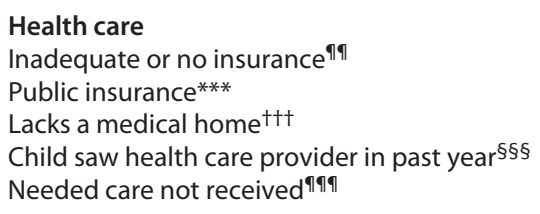 & $\begin{array}{r}33.8(30.2-37.7) \\
51.1(47.2-54.9) \\
58.1(54.3-61.8) \\
90.0(86.3-92.7) \\
\quad 7.0(5.1-9.4)\end{array}$ & $\begin{array}{r}25.4(23.9-27.1) \\
34.4(32.5-36.3) \\
48.2(46.3-50.0) \\
87.6(86.1-88.9) \\
\quad 1.7(1.1-2.5)\end{array}$ & $\begin{array}{l}1.3(1.2-1.5) \\
1.5(1.4-1.6) \\
1.2(1.1-1.3) \\
1.0(1.0-1.1) \\
4.2(2.5-6.9)\end{array}$ & $\begin{array}{l}<0.001^{\S} \\
<0.001^{\S} \\
<0.001^{\S} \\
0.174 \\
<0.001^{\S}\end{array}$ \\
\hline $\begin{array}{l}\text { Family } \\
\text { Fair or poor parental mental health****} \\
\text { Fair or poor parental physical health } \\
\text { Difficult to get by on family's income } \\
\text { Parent lacks emotional support } \\
\text { Chiा }{ }^{\S \S \S \S} \\
\text { Child care problems (ages } 0-5 \text { only)***** }\end{array}$ & $\begin{array}{l}13.7(10.9-17.1) \\
15.7(12.8-19.2) \\
38.0(34.2-42.0) \\
21.2(17.9-24.9) \\
18.8(13.8-25.2)\end{array}$ & $\begin{array}{r}5.7(4.9-6.7) \\
8.1(7.0-9.2) \\
21.3(19.7-22.9) \\
23.3(21.4-25.3) \\
5.3(4.4-6.3)\end{array}$ & $\begin{array}{l}2.4(1.8-3.2) \\
2.0(1.5-2.5) \\
1.8(1.6-2.0) \\
0.9(0.8-1.1) \\
3.5(2.5-5.0)\end{array}$ & $\begin{array}{c}<0.001^{\S} \\
<0.001^{\S} \\
<0.001^{\S} \\
0.299 \\
<0.001^{\S}\end{array}$ \\
\hline 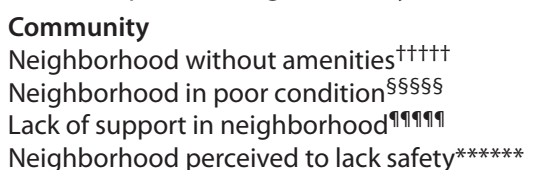 & $\begin{array}{r}65.2(61.3-68.9) \\
26.8(23.4-30.6) \\
35.7(31.7-39.9) \\
6.8(4.8-9.5)\end{array}$ & $\begin{array}{r}60.3(58.5-62.0) \\
24.5(22.8-26.2) \\
26.5(24.7-28.4) \\
5.4(4.4-6.6)\end{array}$ & $\begin{array}{l}1.1(1.0-1.2) \\
1.1(0.9-1.3) \\
1.3(1.2-1.5) \\
1.3(0.8-1.9)\end{array}$ & $\begin{array}{c}0.023^{\S} \\
0.245 \\
<0.001^{\S} \\
0.300\end{array}$ \\
\hline
\end{tabular}

See table footnotes on the next page.

income level decreased), with the exception that inadequate insurance was less often reported for children in the lower income levels than for those in the highest level.

Among children living at $<200 \%$ of FPL, $82.6 \%$ saw a health care provider in the past year, and $73.4 \%$ received public assistance (Table 3). Among the children who did not see a health care provider in the past year, $69.0 \%$ received public assistance and $19.2 \%$ had a diagnosed MBDD. Among children who did not see a health care provider in the past year and had a diagnosed MBDD, $81.7 \%$ received public assistance. Of children who did not see a health care provider in the past year and did not have a diagnosed MBDD, $66.0 \%$ received public assistance.

\section{Discussion}

Consistent with previous studies $(3,5,7)$, this study found that children living in lower-income households had higher prevalences of a parent-reported diagnosis of an MBDD and 
TABLE 1. (Continued) Prevalence of demographic, health care, family, and community factors, by ever having any mental, behavioral, or developmental disorder (MBDD)* among children aged 2-8 years - National Survey of Children's Health, United States, 2016

\begin{abstract}
Abbreviation: $\mathrm{Cl}=$ confidence interval.
* Based on a response of "yes" to whether "a doctor or other health care provider ever told you that this child has" one or more of the following disorders: "anxiety problems, depression, attention-deficit/hyperactivity disorder, behavioral or conduct problems, Tourette syndrome, autism spectrum disorder, learning disability, intellectual disability, developmental delay, or speech or other language disorder."

† Percentages are weighted. Column percentages might not sum to $100 \%$ because of rounding.

$\S p$-value for weighted Wald chi-square test. All p-values $<0.05$ indicate statistically significant differences from "No MBDD."

I Missing data on sex were imputed for $0.1 \%$ of the sample using hot-deck imputation methods.

** Missing data on race and ethnicity were imputed for $0.3 \%$ and $0.5 \%$ of the sample, respectively, using hot-deck imputation methods. "Other, non-Hispanic" includes American Indian/Alaska Native, Native Hawaiian or Other Pacific Islander, and Asian.

$t^{+}$Urban and rural designations were determined using a four-category classification based on 2010 rural-urban community area codes (RUCAs), a census tractbased classification system. Urban areas (RUCA codes 1.0, 1.1, 2.0, 2.1, 3.0, 4.1, 5.1, 7.1, 8.1, and 10.1) include metropolitan areas and surrounding towns from which commuters flow to an urban area; large rural areas (RUCA codes 4.0,5.0, and 6.0) include large towns (micropolitan areas) with populations of 10,000-49,999 and their surrounding areas; small rural areas (RUCA codes 7.0, 7.2, 8.0, 8.2, and 9.0) include small towns with populations of 2,550-9,999 and up to 50\% secondary flow to a large urban cluster of up to 50,000; and isolated areas (RUCA codes 10.0, 10.2, and 10.3) with less than 2,500 population and up to 50\% secondary flow to a large or small urban cluster (population up to 10,000). (https://www.census.gov/geo/reference/ua/urban-rural-2010.html).

$\S \S$ Federal poverty level is based on family income and family size and composition using federal poverty thresholds that are updated annually by the U.S. Census Bureau using the change in the average annual consumer price index for all urban consumers. Imputed income was used for $16.6 \%$ of children aged $2-8$ years with MBDD status and sex reported, but without reported household income, using regression methods.

กๆ Based on a negative value for any of four variables based on these questions: 1) "Is this child currently covered by any kind of health insurance or health coverage plan?" 2) "How often does this child's health insurance offer benefits or cover services that meet this child's needs?" 3) "Does the family pay out-of-pocket expenses," and if yes, "How often are these costs reasonable?" and 4) "How often does this child's health insurance allow him or her to see the health care providers he or she needs?"

*** Based on a response of "yes" to having "Medicaid, Medical Assistance, or any kind of government assistance plan for those with low incomes or a disability."

t+t Based on five component variables (personal doctor or nurse, usual source for sick and well care, family-centered care, problems getting needed referrals, satisfaction with communication, and effective care coordination when needed), derived from 16 survey items. To have a medical home, the child must have a personal doctor or nurse, usual source of care, and family-centered care; children needing referrals or care coordination must also have those criteria met.

$\S \S \S$ Whether the child saw a health care provider in the last 12 months was based on a response of "yes" to the following question: "During the past 12 months, did this child see a doctor, nurse, or other health care professional for sick-child care, well-child check-ups, physical exams, hospitalizations, or any other kind of medical care?"

ๆศๆ Based on a response of "yes" to the following question: "During the past 12 months, was there any time when this child needed health care, but it was not received? By health care, we mean medical care as well as other kinds of care like dental care, vision care, and mental health services."

*** Based on whether either parent reported "fair" or "poor" (i.e., compared with "excellent," very good," or "good") to the question "In general, how is your mental or emotional health?"

ttt† Based on whether either parent reported "fair" or "poor" (i.e., compared with"excellent,"'very good," or "good") to the question:"In general, how is your physical health?"

$\S \S \S$ Based on an answer of "very often" or "somewhat often" (i.e., compared with "never" or "rarely") to the question: "Since this child was born, how often has it been very hard to get by on your family's income (e.g., hard to cover the basics like food or housing)?"

ๆางๆ Based on a response of "no" to the question "During the past 12 months, was there someone that you could turn to for day-to-day emotional support with parenting or raising children?"

***** Based on a response of "yes" to the question: "During the past 12 months, did you or anyone in the family have to quit a job, not take a job, or greatly change your job because of problems with child care for (child)?". Note: This question was asked for children aged 0-5 years only.

t+t+† Based on a response of "no" to any of the following four questions:"In your neighborhood, is/are there: 1) sidewalks or walking paths?; 2) a park or playground?; 3) a recreation center, community center, or boys' and girls' club?; 4) a library or bookmobile?"

$\S \S \S \S \S$ Based on a response of "yes" to any of the following three questions:"In your neighborhood, is/are there: 1) litter or garbage on the street or sidewalk?; 2) poorly kept or rundown housing?; 3) vandalism such as broken windows or graffiti?"

กากๆศศ Based on a response of "definitely disagree" or "somewhat disagree" (i.e., compared with "definitely agree" or "somewhat agree") to any of the following three questions: "To what extent do you agree with these statements about your neighborhood or community? 1) People in this neighborhood help each other out; 2) We watch out for each other's children in this neighborhood; 3) When we encounter difficulties, we know where to go for help in our community."

****** Based on a response of "definitely disagree" or "somewhat disagree" (i.e., compared with "definitely agree" or "somewhat agree") to the following statement: "This child is safe in our neighborhood."
\end{abstract}

other health care, family, and community risk factors associated with MBDDs than did children living in higher-income households. Most children had seen a health care provider in the past year regardless of income level; therefore, the American Academy of Pediatrics recommendation to screen for MBDDs (8) and family and socioeconomic risk factors (4) during primary care visits appears to be theoretically feasible.

Screening ${ }^{* *}, \dagger \dagger$ in health care settings can be challenging in practice, and MBDDs might be underdiagnosed even among

\footnotetext{
** https://www.aap.org/en-us/advocacy-and-policy/aap-health-initiatives/ Screening/Pages/default.aspx.

${ }^{\dagger \dagger}$ https://eclkc.ohs.acf.hhs.gov/publication/birth-5-watch-me-thrivecompendium-screening-measures-young-children.
}

children who have recently seen a health care provider (9). Children living in lower-income households had lower prevalences of having seen a health care provider in the past year and of receiving needed health care compared with children living in higher-income households. Approximately one in five children living at $<200 \%$ of FPL who did not see a health care provider in the past year had a diagnosed MBDD. This, coupled with families with lower incomes reporting greater difficulty receiving needed health care, raises concern that MBDDs might be undertreated in this population. Additionally, families living in poverty were more likely to experience a range of risk factors related to MBDDs; therefore, connections to health care services are especially relevant for this population. 
Morbidity and Mortality Weekly Report

TABLE 2. Prevalence of parental report of any mental, behavioral, or developmental disorder (MBDD), and health care, family, and community factors among children aged 2-8 years, by federal poverty level - National Survey of Children's Health, United States, 2016

\begin{tabular}{|c|c|c|c|c|c|c|c|c|}
\hline \multirow[b]{3}{*}{ Characteristic } & \multicolumn{8}{|c|}{ Percentage of federal poverty level* } \\
\hline & \multirow{2}{*}{$\frac{\geq 400 \% \text { (referent) }}{\%(95 \% \mathrm{CI})^{\dagger}}$} & \multicolumn{2}{|c|}{$200 \%-399 \%$} & \multicolumn{2}{|c|}{$100 \%-199 \%$} & \multicolumn{2}{|c|}{$<100 \%$} & \multirow{2}{*}{$\frac{\text { Overall }}{\%(95 \% \mathrm{Cl})^{\dagger}}$} \\
\hline & & $\%(95 \% \mathrm{Cl})^{\dagger}$ & PR $(95 \% \mathrm{Cl})$ & $\%(95 \% \mathrm{Cl})^{\dagger}$ & PR $(95 \% \mathrm{Cl})$ & $\%(95 \% \mathrm{Cl})^{\dagger}$ & PR $(95 \% \mathrm{Cl})$ & \\
\hline MBDD $§$ & $13.9(12.1-16.0)$ & $16.6(14.1-19.3)$ & $1.2(0.9-1.5)$ & $18.6(15.5-22.1)$ & $1.3(1.1-1.7)^{9}$ & $22.1(18.8-25.9)$ & $1.6(1.3-2.0)^{9}$ & $17.4(16.2-18.7)$ \\
\hline \multicolumn{9}{|l|}{ Health care } \\
\hline Inadequate or no insurance ${ }^{* *}$ & $27.4(25.2-29.7)$ & $33.0(30.2-36.0)$ & $1.2(1.1-1.4)^{\Uparrow}$ & $24.1(20.5-28.0)$ & $0.9(0.7-1.0)$ & $20.7(16.9-25.2)$ & $0.8(0.6-0.9)^{9}$ & $26.9(25.5-28.4)$ \\
\hline Public insurance ${ }^{t \dagger}$ & $6.6(4.7-9.2)$ & $21.8(19.0-24.8)$ & $3.3(2.2-5.0)^{9}$ & $61.6(57.6-65.4)$ & $9.4(6.7-13.2)^{9}$ & $76.3(71.6-80.5)$ & $11.7(8.2-16.6)^{9}$ & $37.3(35.5-39.0)$ \\
\hline Lacks a medical home $\mathrm{e}^{\S \S}$ & $36.7(34.4-39.0)$ & $48.2(45.2-51.3)$ & $1.3(1.2-1.4)^{9}$ & $57.7(53.7-61.7)$ & $1.6(1.4-1.7)^{9}$ & $62.1(57.7-66.4)$ & $1.7(1.5-1.9)^{9}$ & $49.9(48.2-51.5)$ \\
\hline $\begin{array}{l}\text { Child saw health care provider in } \\
\text { past year }\end{array}$ & $93.8(92.4-95.0)$ & $90.1(88.0-91.8)$ & $1.0(0.9-1.0)^{\natural}$ & $84.7(80.8-88.0)$ & $0.9(0.9-0.9)^{\text {n }}$ & $80.4(75.6-84.5)$ & $0.9(0.8-0.9)^{\natural}$ & $88.0(86.6-89.2)$ \\
\hline Needed care not received ${ }^{* * *}$ & $0.8(0.5-1.2)$ & $1.9(1.3-2.7)$ & $2.4(1.4-4.4)^{9}$ & $3.6(2.3-5.6)$ & $4.6(2.4-9.1)^{9,+十 \dagger}$ & $5.0(3.0-8.2)$ & $6.4(3.2-12.6)^{9, \mathrm{tt \dagger}}$ & $2.6(2.0-3.3)$ \\
\hline \multicolumn{9}{|l|}{ Family } \\
\hline Fair or poor parental mental health $\S \S$ & $3.9(2.8-5.5)$ & $6.1(4.3-8.6)$ & $1.6(1.0-2.6)$ & $10.5(7.9-13.7)$ & $2.7(1.7-4.2)^{9}$ & $15.4(12.2-19.1)$ & $3.9(2.6-5.8)^{9}$ & $8.0(7.0-9.1)$ \\
\hline Fair or poor parental physical health ๆศศ & $3.4(2.4-4.7)$ & $8.5(6.5-11.1)$ & $2.6(1.7-3.9)^{9}$ & $14.6(11.5-18.4)$ & $4.4(2.9-6.7)^{9}$ & $21.9(18.1-26.2)$ & $6.6(4.5-9.6)^{\pi}$ & $10.6(9.4-11.8)$ \\
\hline Difficult to get by on family's income ${ }^{* * * *}$ & $6.1(4.8-7.7)$ & $19.9(17.3-22.8)$ & $3.3(2.4-4.5)^{9}$ & $34.6(30.7-38.8)$ & $5.7(4.3-7.5)^{9}$ & $45.0(40.2-50.0)$ & $7.4(5.8-9.4)^{\Re}$ & $24.2(22.7-25.7)$ \\
\hline Parent lacks emotional support ${ }^{\dagger+\dagger \dagger}$ & $13.0(11.1-15.0)$ & $18.2(15.5-21.2)$ & $1.4(1.1-1.8)^{9}$ & $29.2(24.9-34.0)$ & $2.3(1.8-2.8)^{9}$ & $36.9(32.0-42.1)$ & $2.9(2.3-3.5)^{9}$ & $22.9(21.2-24.7)$ \\
\hline Child care problems (ages $0-5$ yrs only) ${ }^{\S \S \S \S}$ & $3.4(2.4-4.6)$ & $8.0(5.7-10.9)$ & $2.4(1.5-3.7)^{9}$ & $7.8(5.4-11.1)$ & $2.3(1.4-3.8)^{9}$ & $10.7(7.9-14.4)$ & $3.2(2.0-5.0)^{9}$ & $7.1(6.0-8.3)$ \\
\hline \multicolumn{9}{|l|}{ Community } \\
\hline Neighborhood without amenities & $51.3(49.0-53.6)$ & $61.6(58.7-64.3)$ & $1.2(1.1-1.3)^{9}$ & $65.6(61.0-69.9)$ & $1.3(1.2-1.4)^{\text {q }}$ & $70.1(65.1-74.7)$ & $1.4(1.3-1.5)^{\Re}$ & $61.1(59.5-62.7)$ \\
\hline Neighborhood in poor condition ${ }^{* * * * *}$ & $15.0(13.3-16.9)$ & $23.2(20.5-26.0)$ & $1.5(1.3-1.8)^{9}$ & $28.4(24.5-32.7)$ & $1.9(1.6-2.3)^{9}$ & $38.1(33.4-42.9)$ & $2.5(2.1-3.0)^{\pi}$ & $24.9(23.4-26.4)$ \\
\hline Lack of support in neighborhood ${ }^{++t+\dagger}$ & $15.5(13.6-17.5)$ & $25.7(22.4-29.2)$ & $1.7(1.4-2.0)^{9}$ & $35.0(30.7-39.6)$ & $2.3(1.9-2.7)^{9}$ & $41.8(37.0-46.8)$ & $2.7(2.3-3.2)^{\pi}$ & $28.0(26.4-29.7)$ \\
\hline 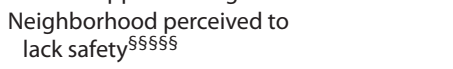 & $1.5(0.9-2.6)$ & $4.6(3.4-6.3)$ & $3.0(1.8-5.2)^{9}$ & $6.7(4.6-9.8)$ & $4.4(2.4-8.2)^{9,+十 \dagger}$ & $11.9(8.6-16.4)$ & $7.9(4.4-14.2)^{9}$ & $5.6(4.7-6.7)$ \\
\hline \multicolumn{9}{|l|}{ Urban/Rural status ศทางๆา } \\
\hline Urban & $94.6(93.8-95.3)$ & $90.2(89.1-91.2)$ & $1.0(0.9-1.0)^{\uparrow}$ & $89.4(87.8-90.9)$ & $0.9(0.9-1.0)^{\text {ๆ }}$ & $87.9(85.5-90.0)$ & $0.9(0.9-1.0)^{9}$ & $90.8(90.1-91.5)$ \\
\hline Large rural & $3.4(2.8-4.1)$ & $5.6(4.9-6.4)$ & $1.6(1.3-2.1)^{9}$ & $6.1(5.0-7.5)$ & $1.8(1.4-2.4)^{9}$ & $6.6(5.1-8.5)$ & $1.9(1.4-2.7)^{9}$ & $5.3(4.8-5.8)$ \\
\hline Small rural & $1.3(1.0-1.7)$ & $2.3(1.8-2.8)$ & $1.7(1.2-2.5)^{9}$ & $2.3(1.8-3.0)$ & $1.8(1.2-2.6)^{9}$ & $3.4(2.5-4.6)$ & $2.6(1.7-3.9)^{9}$ & $2.2(2.0-2.6)$ \\
\hline Isolated & $0.6(0.5-0.9)$ & $2.0(1.5-2.5)$ & $3.0(2.1-4.5)^{9}$ & $2.1(1.5-2.8)$ & $3.2(2.1-5.0)^{9}$ & $2.1(1.3-3.3)$ & $3.2(1.9-5.7)^{9}$ & $1.6(1.4-1.9)$ \\
\hline
\end{tabular}

Abbreviations: $\mathrm{Cl}$ = confidence interval; $\mathrm{PR}$ = prevalence ratio.

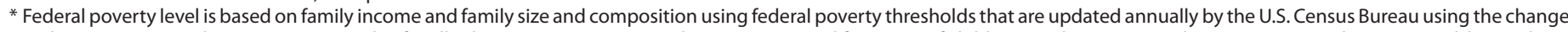

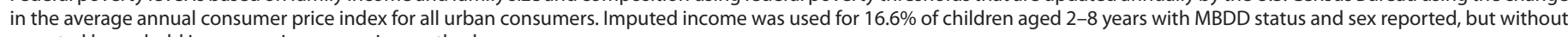
reported household income, using regression methods.

† Percentages are weighted. Column percentages might not sum to $100 \%$ because of rounding.

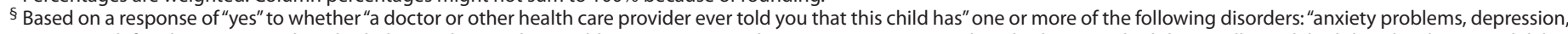

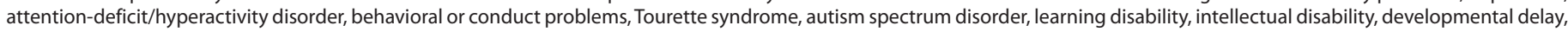
or speech or other language disorder."

I Statistically significant difference from the referent group.

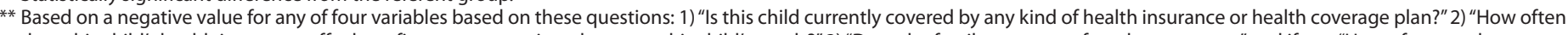

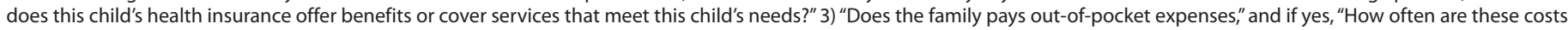
reasonable?" and 4) "How often does this child's health insurance allow him or her to see the health care providers he or she needs?"

†† Based on a response of "yes" to having "Medicaid, Medical Assistance, or any kind of government assistance plan for those with low incomes or a disability."

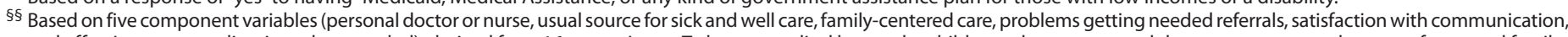

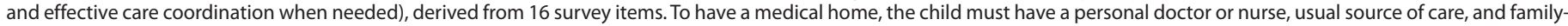
centered care; children needing referrals or care coordination must also have those criteria met.

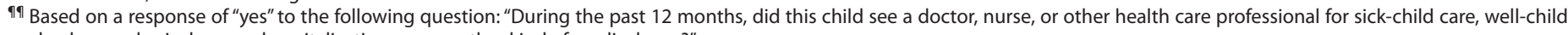
check-ups, physical exams, hospitalizations or any other kind of medical care?"

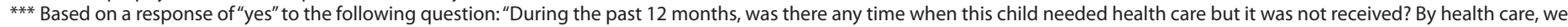
mean medical care as well as other kinds of care like dental care, vision care, and mental health services."

+++ Estimate has a relative standard error $>30 \%$ and might be unreliable.

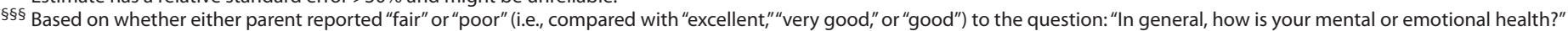

ๆๆ ต Based on whether either parent reported "fair" or "poor" (i.e., compared with "excellent," "very good," or "good") to the question "In general, how is your physical health?"

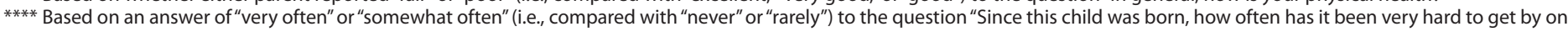
your family's income (hard to cover the basics like food or housing)?"

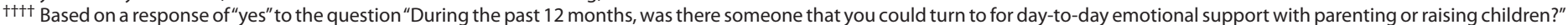

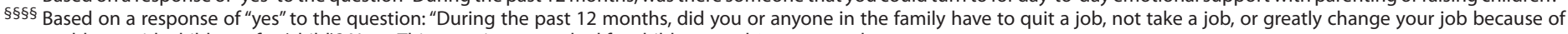
problems with child care for (child)? Note: This question was asked for children aged $0-5$ years only.

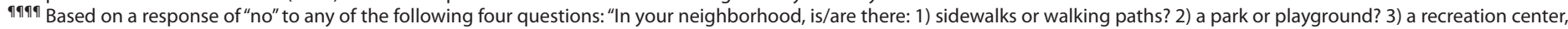
community center, or boys' and girls' club? 4) a library or bookmobile?"

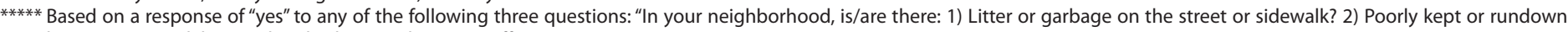
housing? 3) Vandalism such as broken windows or graffiti?"

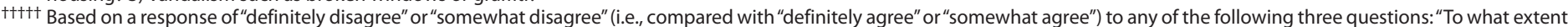

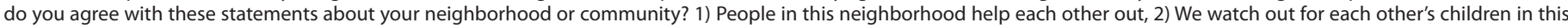
neighborhood, 3) When we encounter difficulties, we know where to go for help in our community."

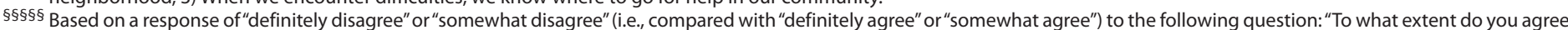
with these statements about your neighborhood or community? 1) This child is safe in our neighborhood."

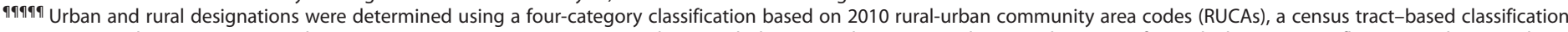

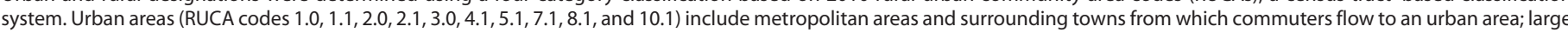

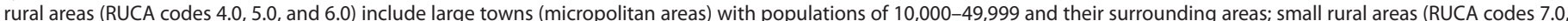

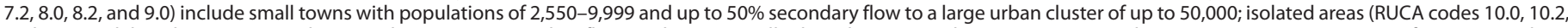

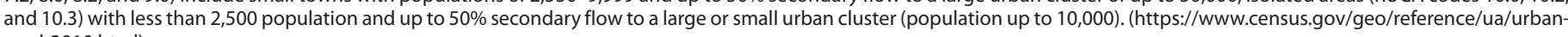
rural-2010.html). 
TABLE 3. Service use among children* living below $200 \%$ of the federal poverty level, by parental report of any mental, behavioral, and developmental disorder (MBDD) - National Survey of Children's Health, United States, 2016

\begin{tabular}{|c|c|c|c|}
\hline & No public assistance ${ }^{\dagger}$ & Public assistance $^{\dagger}$ & Total \\
\hline Characteristic & $\%(95 \% \mathrm{Cl})^{\S}$ & $\%(95 \% \mathrm{Cl})^{\S}$ & $\%(95 \% \mathrm{Cl})^{\S}$ \\
\hline Child saw health care provider in the past year? & $25.7(23.1-28.4)$ & $74.3(71.6-76.9)$ & $82.6(79.7-85.2)$ \\
\hline With MBDD** & $15.1(11.6-19.6)$ & $84.9(80.4-88.4)$ & $21.1(18.5-24.0)$ \\
\hline Without MBDD** & $28.5(25.5-31.7)$ & $71.5(68.3-74.5)$ & $78.9(76.0-81.5)$ \\
\hline Child did not see health care provider in the past yearn & $31.1(24.2-38.7)$ & $69.0(61.3-75.8)$ & $17.4(14.8-20.3)$ \\
\hline With MBDD** & $18.3^{+\dagger}(9.1-33.3)$ & $81.7(66.7-90.9)$ & $19.2(13.0-27.5)$ \\
\hline Without MBDD** & $34.0(26.1-42.9)$ & $66.0(57.1-73.9)$ & $80.8(72.5-87.0)$ \\
\hline Total & $26.6(24.1-29.2)$ & $73.4(70.8-75.9)$ & - \\
\hline
\end{tabular}

Abbreviation: $\mathrm{Cl}=$ confidence interval.

* Restricted to nonmissing responses for child MBDD status, whether the child's family received public assistance, and whether the child saw a health care provider in the past year.

† Based on whether the parent reported the family received any of the four benefits (cash assistance; Women, Infants, and Children; Supplemental Nutrition Assistance Program; or free or reduced cost meals at school) at any time during the past 12 months.

$\S$ Percentages are weighted. Column and row percentages might not sum to $100 \%$ because of rounding.

" Based on response to the following question: "During the past 12 months, did (child) see a doctor, nurse, or other health care professional for sick-child care, wellchild check-ups, physical exams, hospitalizations, or any other kind of medical care?"

** Based on response to whether "a doctor or other health care provider ever told you that this child has" one or more of the following disorders: "anxiety problems, depression, attention-deficit/hyperactivity disorder, behavioral or conduct problems, Tourette syndrome, autism spectrum disorder, learning disability, intellectual disability, developmental delay, or speech or other language disorder."

${ }^{+\dagger}$ Estimate is unstable; relative standard error $=33.3 \%$.

Public assistance programs might provide opportunities to connect families living in poverty to services, in line with the American Academy of Pediatrics call for collaboration between public health professionals and pediatricians (10). Where treatment resources are available, education or early identification programs could be embedded within services families are already accessing. For example, CDC's Learn the Signs. Act Early program connects WIC staff members with resources for parents about early identification of developmental delays and helps staff with referrals to primary care. ${ }^{\$ S}$ Similar approaches to promoting parental awareness of MBDDs and the value of pediatric screening, if carefully designed to minimize stigmatization, could be implemented within other public assistance programs. Identification of MBDDs and associated risk factors (e.g., poor parental mental health or lack of support) and connection to services can be challenging for families, even among those with primary care. Therefore, expanded co-location of developmental and behavioral health services in public assistance programs, as well as other sites that would reach additional families (e.g., schools or early-learning settings, federally qualified health centers, 99 or federal partnerships ${ }^{* * *}$ ), might help to eliminate barriers to care for families living in poverty. ${ }^{\dagger \dagger}, \$ \$ \$$

\footnotetext{
\$\$ https://www.cdc.gov/ncbddd/actearly/wic-providers.html.

99 https:/www.hrsa.gov/opa/eligibility-and-registration/health-centers/fqhol index.html.

*** https://healthysafechildren.org/grantee/project-launch.

$\dagger \dagger$ https://www.milbank.org/publications/behavioral-health-integration-inpediatric-primary-care-considerations-and-opportunities-for-policymakersplanners-and-providers/.

$\$ \$ \$$ https://www2.ed.gov/about/inits/ed/earlylearning/files/health-early-learningstatement.pdf.
}

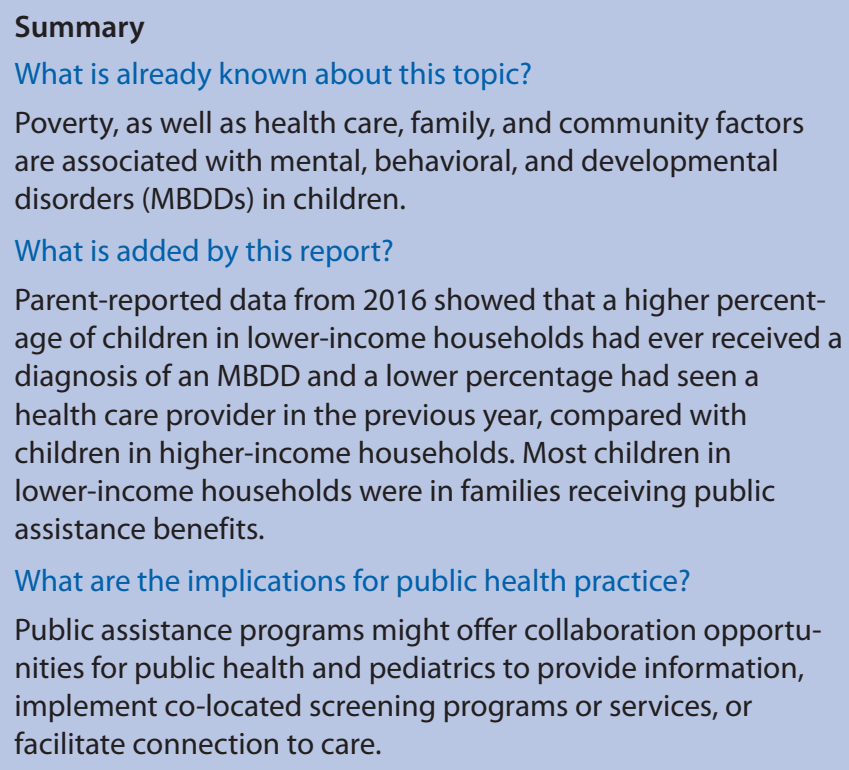

The findings in this report are subject to at least three limitations. First, data are cross-sectional, so it was not possible to ascertain temporal associations or causality. Second, the sampling weights used to calculate nationally representative estimates might not completely compensate for nonresponse bias. Finally, indicators rely on parental report and might be subject to recall or social desirability bias.

Early identification and treatment of MBDDs could positively impact a child's functioning and reduce the need for costly interventions over time (8). Public assistance programs hold potential for increasing developmental monitoring and connection to treatment for MBDDs for families living in 
poverty by collaborating to distribute resources, implementing co-located screening services, or facilitating connections to appropriate treatment and care.

Corresponding author: Robyn A. Cree, nru7@cdc.gov, 404-498-5300.

${ }^{1}$ Epidemic Intelligence Service, CDC; ${ }^{2}$ Division of Human Development and Disability, National Center on Birth Defects and Developmental Disabilities, CDC; ${ }^{3}$ Division of Congenital and Developmental Disorders, National Center on Birth Defects and Developmental Disabilities, CDC; ${ }^{4}$ Office of Epidemiology and Research, Maternal and Child Health Bureau, Health Resources and Services Administration, Rockville, Maryland.

All authors have completed and submitted the ICMJE form for disclosure of potential conflicts of interest. No potential conflicts of interest were disclosed.

\section{References}

1. National Research Council and Institute of Medicine. Preventing mental, emotional, and behavioral disorders among young people: progress and possibilities. Washington, DC: The National Academies Press; 2009.

2. Evans GW, Cassells RC. Childhood poverty, cumulative risk exposure, and mental health in emerging adults. Clin Psychol Sci 2014;2:287-96. https://doi.org/10.1177/2167702613501496

3. Bitsko RH, Holbrook JR, Robinson LR, et al. Health care, family, and community factors associated with mental, behavioral, and developmental disorders in early childhood-United States, 2011-2012. MMWR Morb Mortal Wkly Rep 2016;65:221-6. https://doi.org/10.15585/mmwr. mm6509a1
4. Council on Children With Disabilities Section on Developmental Behavioral Pediatrics, Bright Futures Steering Committee, Medical Home Initiatives for Children With Special Needs Project Advisory Committee. Identifying infants and young children with developmental disorders in the medical home: an algorithm for developmental surveillance and screening. Pediatrics 2006;118:405-20. https://doi. org/10.1542/peds.2006-1231

5. American Academy of Pediatrics Council on Community Pediatrics. Poverty and child health in the United States. Pediatrics 2016;137:e20160339. https://doi.org/10.1542/peds.2016-0339

6. Black LI, Nugent CN, Vahratian A. Access and utilization of selected preventive health services among adolescents aged 10-17. No. 246. NCHS Data Brief 2016.

7. Robinson LR, Holbrook JR, Bitsko RH, et al. Differences in health care, family, and community factors associated with mental, behavioral, and developmental disorders among children aged $2-8$ years in rural and urban areas-United States, 2011-2012. MMWR Surveill Summ 2017;66:1-11. https://doi.org/10.15585/mmwr.ss6608a1

8. American Academy of Pediatrics. Bright futures: guidelines for health supervision of infants, children and adolescents, 4th ed. Elk Grove Village, IL: American Academy of Pediatrics; 2017.

9. Weitzman C, Wegner L; Section on Developmental and Behavioral Pediatrics, Committee on Psychosocial Aspects of Child and Family Health, Council on Early Childhood, Society for Developmental and Behavioral Pediatrics. Promoting optimal development: screening for behavioral and emotional problems. Pediatrics 2015;135:384-95. https://doi.org/10.1542/peds.2014-3716

10. Kuo AA, Thomas PA, Chilton LA, Mascola L; Council on Community Pediatrics. Pediatricians and public health: optimizing the health and well-being of the nation's children. Pediatrics 2018;141:e20173848. https://doi.org/10.1542/peds.2017-3848 